\title{
Première mondiale du World Doctors Orchestra: un rêve devenu réalité
}

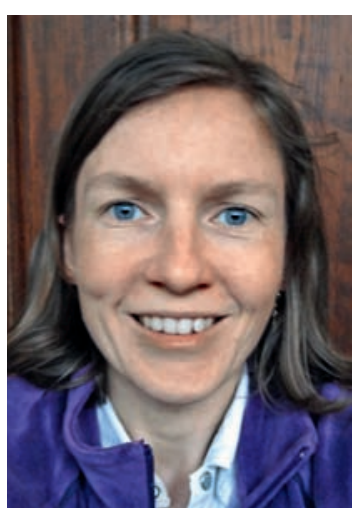

Sandra Krüger

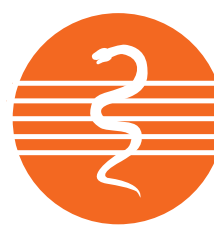

WORLD

DOCTORS

ORCHESTRA

L'idée du premier orchestre mondial de médecins a germé il y a quelque temps déjà. Depuis 2007, le Prof. Stefan Willich, responsable de l'Institut de médecine sociale de l'hôpital universitaire de la Charité à Berlin, et ses collègues œuvrent sérieusement à sa mise sur pied. Ils ont fait paraître des annonces dans les revues médicales du monde entier et élaboré un site Internet qui fournit des informations détaillées sur l'orchestre et y présente son actualité.

Lorsque j'en ai entendu parler pour la première fois, j'ai été très enthousiaste. J'ai donc envoyé ma candidature et j'ai reçu les partitions deux mois avant les répétitions. J'étais très fière de faire partie du cercle des élus. Dès lors, il a fallu se mettre à répéter sans relâche, car le pro-

\section{Les médecins s'engagent pour une prise en charge médi- cale de tous les êtres humains, et ce indépendamment d'intérêts politiques, économiques ou nationaux}

\footnotetext{
* Le Dr Sandra Krüger, spécialiste en médecine du sport en formation postgraduée en vue du titre en orthopédie, écrit régulièrement pour notre journal et est violoniste au sein du World Doctors Orchestra.
}

gramme comportait des pièces exigeantes telles que l'ouverture de «L'élixir d'amour» de Donizetti, le Concerto pour violon de Beethoven ou la $9^{e}$ Symphonie de Dvořák.

Prof. Stefan Willich, responsable de l'orchestre et violoniste, musicien de chambre et chef d'orchestre, a choisi ses collègues musiciens parmi les deux cents dossiers qui lui sont parvenus du monde entier. Qu'ils soient généraliste israélien ou psychiatre australien, tous les membres de l'orchestre ont suivi, outre leurs études de médecine, une formation musicale de plusieures années. Le résultat de l'engagement de ces médecins, qui financent eux-mêmes leurs frais de voyage et d'hébergement, va à deux projets d'entraide médicale. En effet, les recettes de la vente des billets sont destinées à un Hôpital du Sud de l'Inde qui traite principalement des lépreux, et à la Fondation Hugo Tempelman qui soutient une clinique dans le township Elandsdoorn en Afrique du Sud. Cette clinique s'occupe de patients sidéens et de prévention de la tuberculose. Le violoniste de Boston Peter Zazofsky, qui brillait déjà à l'orchestre philarmonique de Berlin en 1983, accompagne le World Doctors Orchestra en qualité de soliste.

80 médecins en provenance de 20 nations ont été invités. La première répétition s'est tenue le $1^{\text {er }}$ mai. Nous étions tous excités, curieux et enthousiasmés par ce magnifique projet. Le chef d'orchestre était particulièrement nerveux, se demandant si ce projet allait se concrétiser. Ce n'est qu'après avoir joué Dvořák ensemble que la nervosité est retombée, véritable soulagement pour le prof. Willich. L'après-midi nous avons exercé les détails du répertoire sous la direction de musiciens professionnels. Je profite de cette occasion pour les remercier encore une fois chaleureusement.

Lors de la première rencontre de l'orchestre le 2 mai, nous avons pu envisager notre avenir. L'ambiance est bonne, le plaisir de la musique nous unit et il est intéressant de rencontrer des collègues du monde entier. Toutefois, notre but n'est pas artistique, nous voulons poser des jalons et montrer qu'il est possible de s'engager pour les soins médicaux dans le monde, tant sur le plan des idées que financièrement, au-delà des frontières nationales et sans appartenance politique ni intérêt économique. Grâce à ses concerts de bienfaisance, le World Doctors Orchestra allie l'utile à l'agréable, dans le but de sensibiliser le grand public à une prise de conscience sociale globale. Les soins médicaux sont un droit fondamental et une condition nécessaire à toute vie humaine.

Après trois jours d'intenses répétitions, un concert pour les patients sous forme de répétition générale a été donné l'après-midi du 3 mai à l'hôpital de la Charité à Berlin. La première mondiale a eu lieu le 4 mai 2008 à 20 h dans une des salles de la Philharmonie de Berlin. L'enthousiasme était grand, et notre rêve était devenu réalité. Désormais, nous envisageons l'avenir avec espoir. Pour 2009, d'autres concerts de bienfaisance sont prévus, également hors d'Europe. Le World Doctors Orchestra pourra donc continuer à faire entendre ses idées.

Sandra Krüger* 